\title{
A Degree Account of Exclamatives
}

\author{
Jessica Rett \\ Rutgers University and \\ University of California, Los Angeles
}

\section{Introduction}

\subsection{Overview}

In this paper, I propose a semantic account of exclamations. The account relies on an important distinction between 'proposition exclamations' (exclamations expressed with declarative sentences, as in 1) and 'exclamatives' (exclamations expressed with $w h$-clauses, definite DPs and inversion constructions, as in 2).

(1) Sue wore orange shoes!

(2) a. (My,) How orange Sue's shoes were!

b. (Oh,) The shoes Sue wore!

c. (Boy,) Did Sue wear orange shoes!

This distinction is based on the empirical observation that the latter are subject to two semantic restrictions not applicable to the former.

The proposal is this: for the utterance of an exclamation to be expressively correct, its content must be salient, and the speaker must find this content surprising. For the utterance of an exclamative to be expressively correct, its content must additionally be about a degree, and that degree must exceed a contextually relevant standard. I account for this difference by proposing that proposition exclamations and exclamatives are expressed with two different illocutionary force operators. These operators have different domains (one is a function from propositions, the other from degree properties) but the same value (an expression of surprise).

This view of exclamatives helps characterize the syntactic constructions used to express exclamatives (which on first glance do not appear to form a natural class). Exclamatives are additionally interesting because, as Milner (1978) and Gérard (1980) observe, they are different from any other expression because they can receive an extreme degree interpretation in the absence of overt degree morphology. The situation is even more compelling than this: as I argue, exclamatives must receive an 'extreme degree' interpretation. Although the discussion here bears quite a bit on what it means for an exclamative to force an 'extreme degree' reading, in the end I will have little to say about how this is so.

Thanks to Mark Baker, Veneeta Dayal, Jane Grimshaw, Angelika Kratzer and Roger Schwarzschild for their comments on earlier versions of this paper. Thanks also to audiences at the UCLA Syntax/Semantics Seminar and of course at SALT XVIII for comments and discussion. Roger Schwarzschild helped with Hebrew judgments and Flavia Adani with Italian judgments. 
I'll begin the discussion of exclamations by considering their place in speech act theory. This discussion will result in the two semantic properties of exclamations generally which I introduced above. I'll then talk about those semantic properties specific to exclamatives by examining the Degree Restriction and then the Evaluativity Restriction.

\subsection{Speech acts and exclamation}

When uttering a sentence, a speaker performs a speech act. A speech act is characterized in terms of the communicative function of the utterance (Austin 1962, Searle 1969), and has two components: its semantic content, and the illocutionary force with which that content is uttered. (3), uttered with the right sort of intonation, is an example of an assertion.

(3) Sue wore orange shoes.

The semantic content of (3) is the proposition that Sue wore orange shoes. Its illocutionary force is one of assertion, in which the speaker can be thought of as believing the content and wanting to communicate the truth of the content.

Exclamations are a different kind of speech act with a correspondingly different illocutionary force. For instance (4) (repeated from 1), when uttered with emphasis and a falling intonation (Bartels 1999: 263), is an exclamation.

Sue wore orange shoes!

As with assertions, exclamations have content - here, the proposition that Sue wore orange shoes - and illocutionary force. The illocutionary force of exclamation is one in which the speaker believes the content and wants to communicate that the content is surprising.

While assertions are descriptively (in)correct, expressives like the exclamation in (4) are expressively (in)correct (Kaplan 1999). The utterance of an exclamation is expressively correct if its content is salient and the speaker finds this content surprising (or contrary to expectations). As an example, an utterance of (4) would be expressively correct if the speaker is surprised that Sue wore orange shoes (perhaps because he expected her to wear black shoes), and the color of Sue's shoes was salient in the discourse. ${ }^{1}$

The fact that the illocutionary force of exclamation communicates that the speaker finds the content surprising accounts for the intuitive differences between (3) and (4). It also explains why someone would be offended if, on meeting them for the first time, I exclaimed, (Oh,) You don't look like a warthog!

\footnotetext{
${ }^{1}$ I intend to speak about the nature of this surprise very loosely. As Angelika Kratzer (p.c.) points out, an expressively correct utterance of an exclamative doesn't require that the speaker himself be surprised at the content of the exclamation. He need only consider it surprising in some capacity. Imagine a scenario in which the speaker knows that Sue wore orange shoes but also knows that his audience will find the fact surprising. It still seems expressively correct, in this case, for him to utter (4) with exclamation illocutionary force.
} 
Of course, expressives can be uttered insincerely, as can other types of speech acts like promises (but not like e.g. christenings, Searle 1969: 65). This is what accounts for the fact that I can exclaim What a nice house you have! on seeing your house for the first time even when it is exactly as nice as I had expected it to be (contra Zanuttini and Portner 2003). These insincere uses provide insight into discourse considerations like politeness, but not into the meaning of the illocutionary force itself. Even if the speaker was to utter the above exclamation insincerely, it would still be reasonable for the hearer to assume that it was a sincere utterance, in which case the hearer would be flattered that the speaker was impressed by the house.

A note about one particular consequence of this view of exclamatives: encoding what it means to be an exclamative in the illocutionary force of an utterance means that there is no such thing as an embedded exclamative. An illocutionary force is a property of an utterance as a whole, not of subcomponents of utterances. This means that my use of the terms 'exclamation' and 'exclamative' apply only to matrix clauses, never embedded ones.

It has been commonplace since Elliott (1974) and Grimshaw (1977) to discuss the differences between the two readings of the embedded wh-clause in (5) as attributable to the fact that this clause is ambiguous between an embedded question and an embedded exclamative.

John knows how tall the building is.

The former structure corresponds to a reading in which the building is 50 meters tall and John knows it; the latter to a reading in which the building is tall relative to a contextual standard and John knows it. In Rett (2008b) I provide an alternative characterization of this ambiguity, maintaining that exclamation is an illocutionary force and therefore not a property of embedded clauses.

\section{Semantic restrictions on exclamatives}

We now have two requirements for what makes the utterance of an exclamation expressively correct: its content must be salient, and the speaker must find this content surprising in some way. As I mentioned above, these requirements are sufficient to describe the semantics of proposition exclamations, but are not sufficient for exclamatives. Exclamatives are subject to two additional semantic restrictions: their content must be about a degree, and this degree must exceed a relevant standard. I will demonstrate these restrictions first using $w h$-exclamatives, and will begin with the Degree Restriction.

\subsection{The Degree Restriction}

It is not just the case that exclamatives can receive a degree interpretation, as Milner and Gérard point out; they must receive a degree interpretation. I will demonstrate 
this by discussing possible interpretations of the wh-exclamative What languages Mimi speaks!. The first two interpretations I discuss confirm that this exclamative can have readings that involve degrees; the third shows that this exclamative cannot have a reading that does not involve degrees.

\subsubsection{The amount reading}

Imagine a scenario in which Mimi is an American, and so you expect her to speak only one language (English). You are therefore surprised to learn that she speaks 10 other languages. You can use either the proposition exclamation in (6a) or the wh-exclamative in (6b) to express your surprise at this fact.

a. (Wow,) Mimi speaks 11 languages!

b. (My,) What languages Mimi speaks!

This is the amount reading of the exclamative in (6b): the content of the wh-clause seems to be about quantities of languages. In this way, it can be used to exclaim about the same circumstance as the proposition exclamation in (6a).

The amount reading is available despite the fact that $(6 \mathrm{~b})$ does not contain any overt degree morphology (e.g. 11 or many). Accounting for how this is so is fairly straightforward. Following work in Cresswell (1976) and elsewhere, I have proposed a null quantity operator QUANTITY which associates individuals with degree arguments corresponding to their quantity (where $\mu$ measures the size of a plural individual $X$; Rett 2008b: Chapter 2).

$$
\llbracket \mathrm{QU} \text { ANTITY } \rrbracket=\lambda P \lambda d \lambda Q \exists X[P(X) \wedge Q(X) \wedge \mu(X)=d]
$$

In other constructions, QUANTITY allows for the modification of NPs by e.g. measure phrases (MPs). In the case of exclamatives, QUANTITY provides a degree argument for the wh-phrase what in (6b).

This use of (6b) is an instance of one available degree reading.

\subsubsection{The gradable reading}

Imagine a scenario in which Mimi is a Romance linguist, and so you expect her to speak only Romance languages. However, you come to learn that she additionally speaks languages from several obscure language families.

a. (Wow, Mimi speaks exotic languages!

b. (My,) What languages Mimi speaks!

In (8b), the same exclamative receives a gradable interpretation: the speaker uses it to express surprise at the fact that the languages Mimi speaks are exotic to degree $d$. This reading is unambiguously available in the exclamative What exotic languages Mimi speaks!, but the fact that (8b) is expressively correct here indicates, as the Milner/Gérard Generalization predicts, that $(8 \mathrm{~b})$ can receive a gradable interpretation 
despite not containing any overt degree morphology.

It is standard to propose that $(8 \mathrm{~b})$ involves a covert gradable predicate $\mathbb{P}$ which receives its value from context (Milner 1978, Gérard 1980, Gutiérrez-Rexach 1996, Villalba 2003, Castroviejo-Miró 2006). So in this context, $\mathbb{P}$ can be 'exotic,' while in other contexts, it could be 'easy' or 'difficult'.

Although I have no account of the possible distribution of $\mathbb{P}$ outside of exclamatives, the ability to force a gradable interpretation out of forms without overt degree morphology seems to extend to other constructions as well.

(9) a. That's quite a turkey you have there! (read: good, large, crazy, etc.)

b. She bought SOME pizza. (read: delicious, expensive, large, etc.)

However, the distribution of $\mathbb{P}$ is clearly somewhat restricted, judging from the inability of e.g. (9b) to have this degree reading if some is not stressed (or replaced by another indefinite, like $a$ ).

\subsubsection{The individual reading}

The two scenarios above demonstrate two different readings of a single wh-exclamative, and they have in common the fact that they are exclamations about degrees. However, since What languages Mimi speaks! is headed by the wh-phrase what, and since what can range over individuals in every other construction in which it occurs, we might think that this exclamative can also receive an individual interpretation. This is not the case.

Imagine a scenario in which you've heard that Mimi speaks two Romance languages in addition to speaking English. You know that Mimi's mother is Swiss, and so you assume that these two languages are French and Italian. However, you learn that Mimi instead speaks Portuguese and Romanian.

a. (Wow,) Mimi speaks Portuguese and Romanian!

b. \#(My,) What languages Mimi speaks!

As before, (10a), the proposition exclamation, is expressively correct in this scenario. However (10b), the exclamative, is not. Specifically, the exclamative cannot be used to express surprise that Mimi speaks two particular languages (Portuguese and Romanian). ${ }^{2}$

Here's another example to stress the point: some friends are playing a card game, and it's Mac's turn to pick a series of pairs from the deck. He picks the ace of spades and the king of diamonds. The cards are shuffled back in and he picks another pair, and again he chooses the ace of spades and the king of diamonds. Again the cards are reshuffled and for a third time, Mac picks the ace of spades and the king of diamonds. In this scenario, (11a) is expressively correct but (11b) is not.

\footnotetext{
${ }^{2}$ This utterance can be coerced into being expressively correct in this scenario if one were to come up with a salient gradable property which is shared by Portuguese and Romanian (but not French and Italian). In such a situation, the relevant reading ceases to be an individual one, and is instead a gradable one.
} 
a. (Wow, Mac picked the ace of spades and king of diamonds (again)!

b. \#(My,) What cards Mac picked!

In other words, (11b) cannot be used to express surprise that Mac picked out those two particular cards.

There are many theories in which this fact goes unaccounted for. Zanuttini and Portner (2003) presents a theory of the syntax and semantics of exclamatives which has recently been influential. In it, exclamatives have a form and meaning which roughly parallel those of questions. They denote a set of propositions, but additionally involve a 'domain widener' which allows the denotation to reflect not only the true propositions $p$ which are discourse-salient but all true propositions $p$.

In their theory, this domain widener provides the semantic thrust of an exclamative, and it takes as its argument a set of propositions. Because there is no formal difference between a set of propositions denoted by a degree question and a set of propositions denoted by an individual question, this theory (and others for which the exclamative operator is a function from a proposition or a set of propositions) cannot account for the Degree Restriction.

The next section strengthens the claim that an analysis of exclamatives needs to account for the Degree Restriction by demonstrating this restriction in other exclamatives as well.

\subsubsection{Degrees and how-exclamatives}

I've illustrated the Degree Restriction with a wh-exclamative headed by what, but it holds for exclamatives headed by other $w h$-phrases as well. The $w h$-phrases which can head wh-exclamatives in English are restricted to those which can range over degrees (I include what in this category because of independent observations that its range is underspecified; see the discussion in Rett 2008b). Thus, the exclamatives in (12) are ungrammatical.

a. *Who/Which people he associates with!

b. *When/Where she studies!

c. *Why she bought that pony!

In English, this is further evidence for the Degree Restriction: the morphology of the exclamatives in (12) prevents them from having degree interpretations. ${ }^{3}$

Exclamatives headed by how many can only have amount readings, so their interpretation is straightforward. Exclamatives headed by how, on the other hand,

\footnotetext{
${ }^{3}$ Some of the exclamatives in (12) are grammatical in other languages; Zanuttini and Portner (2003) report that exclamatives headed by e.g. who are grammatical in Paduan and Italian. My Italian informants report that these exclamatives, too, are subject to the Degree Restriction: Who she met at the party! is like the English (Oh,)The people she met at the party! in that it can be used to express surprise that the people she met were particularly $P$ (fun, famous) but not that she met a few particular surprising people. This indicates that the cross-linguistic difference is not about adherence to the Degree Restriction, but instead about whether or not a particular wh-phrase can range over degrees.
} 
require a little more discussion. Judging from its behavior in questions, how is able to range over manners as well as evaluations (and of course gradable degrees, as in How short you are!).

How does Buck ride his horse?

a. manner: bare-backed, saddled

b. evaluation: beautifully, dangerously, clumsily...

Only evaluations are gradable, which means that we predict given the Degree Restriction that how in exclamatives can only range over evaluations.

This is in fact the case. The exclamative (My,) How Buck rode his horse! is expressively correct in a scenario in which the speaker expected Buck to ride poorly but he instead rode beautifully. It is not expressively correct in a scenario in which the speaker expected Buck to ride bare-backed and he instead rode saddled. As with the gradable interpretation of (My,) What languages Mimi speaks!, the exclamative How Buck rode his horse! does not involve any overt degree morphology. Just as we postulated a null gradable adjective $\mathbb{P}$ to account for the gradable reading, we can postulate here a null gradable adverb ADV to account for the evaluation interpretation.

To sum up the discussion of the Degree Restriction: wh-exclamatives are incapable of receiving an interpretation in which the speaker is expressing surprise at something which is not a degree (an individual or a manner). This restriction does not seem to be contributed by the wh-phrases heading these constructions, which are often synonymous with heads of questions and relative clauses that do not have similar restrictions. The Degree Restriction is also not an effect of the speech act of exclamation, as proposition exclamations can but need not be used to express surprise that a certain degree property holds of a certain degree.

Before presenting an account of wh-exclamatives, I'll discuss one further semantic restriction on them. It is related to the Degree Restriction, but is useful to discuss separately.

\subsection{The Evaluativity Restriction}

I've argued above that an utterance of an exclamation is expressively correct if it is used to express surprise at the content of the exclamation, and if this content is salient. I've further argued for $w h$-exclamatives that they are only expressively correct if this semantic content is about degrees in a particular way. These requirements are not quite sufficient to describe the conditions under which a wh-exclamative is expressively correct. The content of the exclamative must additionally be objectively surprising; specifically, the degree in question must be high relative to a contextual standard.

There is some morphological evidence from English and Catalan (based on Castroviejo-Miró 2006) for this restriction (Rett 2008b); I will keep things relatively simply by just illustrating this restriction in terms of scenarios in which an exclamative is expressively correct. 
Imagine a scenario in which Luke expects Duke's children to be extremely short (say, because Duke and his wife are extremely short). Specifically, he expects their 12-year-old Manny to be 3 and a half feet tall. In fact, Manny is 4ft tall, which, say, is still relatively short for a 12 -year-old boy. In this scenario, it seems expressively incorrect for Luke to utter (14):

$$
\text { \#(My,) How tall Manny is! }
$$

If the requirement on expressively correct utterances of exclamatives were only that the speaker be surprised about a degree, we might predict that Luke's utterance of (14) would be expressively correct because Manny is taller than Luke expected him to be. But in fact, (14) is bad, and this seems to be because Manny is not in fact tall. This indicates that exclamatives are also restricted so that their content is about a degree which exceeds a relevant contextual standard.

In other work, I've referred to this property as 'evaluativity'; an expression is evaluative if it makes reference to a degree that exceeds a standard. This property is traditionally associated with positive constructions like John is short, but is clearly prevalent across degree constructions. Rett (2008a) and Rett (2008b: Chapter 3 ) provide an extensive account of the distribution of evaluativity; for now, it is sufficient to just point out that evaluativity is part of the meaning of exclamatives.

This concludes the empirical discussion of $w h$-exclamatives. The next section provides an analysis which accounts for the differences between proposition exclamations and exclamatives based on these observations. Section 4 extends the analysis to other types of exclamatives, those expressed with definites and inversion constructions.

\section{An analysis of exclamatives}

All exclamations have in common the fact that, in order to be uttered expressively correctly, their content must be salient, and the speaker must find the content surprising. In other words, the speaker must know that $p$ and be surprised that $p$. Given our assumptions that these restrictions on the expressive correctness of exclamations are imposed by the illocutionary force of exclamation, we can account for the meaning of exclamations by formulating the illocutionary force operator used to express them.

\subsection{Proposition exclamations}

We can reason from the discussion above that the illocutionary force operator of exclamation is a function from a proposition to a speaker's expression of surprise. This is particularly straightforward because proposition exclamations are formed from declarative sentences and their content is therefore a proposition. Below is the definition of the illocutionary force operator of exclamation ('E-FORCE') used to express proposition exclamations. 
Proposition E-ForCE $(p)$ is expressively correct in context $C$ iff $p$ is salient in $C$ and the speaker in $C$ is surprised that $p$.

The proposition exclamation Sue wore orange shoes!, then, is an instance of the proposition Sue wore orange shoes expressed with Proposition E-FORCE, and this utterance is expressively correct if Sue's having worn orange shoes is salient in the context of utterance, and if the speaker of the utterance is surprised that Sue wore orange shoes.

The meaning of the illocutionary force operator in (15) should strike you as very similar to the meaning of the embedding verb be surprised that, as in the assertion I am surprised that Sue wore orange shoes. Both E-FORCE and be surprised that take a sentence $S$ as their argument and express surprise on the part of the speaker that that proposition denoted by $S$ is true. The important difference between the two is how this meaning is encoded. The illocutionary force operator encodes this meaning in a speech act of exclamation, while be surprised that encodes it as part of a speech act of assertion.

That said, the predicate be surprised can provide an important insight into illocutionary force operators of exclamation. Take the pair in (16):

a. I am surprised [CP that Blue is so old.]

b. I am surprised [PP at [CP how old Blue is.]]

Intuitively, one can only be surprised at a proposition, but this intuition is clouded by the fact that surprise can take complements which do not appear propositional. The natural conclusion to draw from this data is that surprise in (16b) (or its complement) is associated with a type-shifter which is a function from the content of the complement to a proposition (see, for instance, Partee 1987). This reconciles our assumptions about the semantics of surprise with the semantic type of its complement in (16b). It also provides some insight into the illocutionary force operator used to express exclamatives.

\subsection{Wh-exclamatives}

There are two reasons why it's clear that wh-exclamatives are not uttered with Proposition E-FORCE. The first is that it seems odd to think of the wh-clauses used to express exclamatives as denoting propositions. The second is that Proposition E-FORCE is not capable of restricting the content of an exclamation to content involving evaluative degrees. This is so for the same reason that e.g. Zanuttini and Portner's (2003) theory is incapable of accounting for the Degree Restriction (see Section 2.1): there is no formal way of distinguishing a proposition or a set of propositions about degrees and about individuals.

So it seems as though $w h$-exclamatives are uttered using a different illocutionary force operator, one which results in an expression of surprise like Proposition E-FORCE, but one whose domain is not a proposition. If the content of a wh-exclamative was instead a degree property, it could be essentially type-shifted 
into a proposition by the illocutionary force operator used to utter wh-exclamatives (as with the complement to the verb be surprised in 16b).

Degree E-ForCe $(\mathscr{D}\langle d,\langle s, t\rangle\rangle)$ is expressively correct in context $C$ iff $\mathscr{D}$ is salient in $C$ and $\exists d, d>s$ [the speaker in $C$ is surprised that $\lambda w . \mathscr{D}(d)(w)]$.

Given (17), the utterance of an exclamative is expressively correct if its content is a degree property which is salient in the discourse, the speaker is surprised that a specific degree holds of that degree property, and that degree exceeds a contextually provided standard $s$ (for a dicussion of how this standard is valued, see Kennedy 2007). Although the content of a wh-exclamative is a degree property, the contribution of the exclamative to the discourse is still the expression of surprise at a proposition (surprise that a particular degree property holds of the degree $d$ ).

There are a few immediate consequences of this proposal that hold true. First, because the illocutionary force operator associated with $w h$-exclamatives binds a free degree argument - and because each utterance can presumably be expressed with only one illocutionary force operator - we predict that expressions uttered with Degree E-FORCE can have at most one free degree argument. This suggests that exclamatives expressed with multiple- $w h$-clauses are unacceptable, which is in fact the case. Huddleston (1993) makes this point for exclamatives like (18a), but we predict these to be ungrammatical because they cannot receive a degree interpretation. The exclamative in (18b), in which both $w h$-phrases range over degrees, is also unacceptable.

a. *Who married which person!

b. *How very fat how very many people are!

Second, I've posited two illocutionary force operators, one whose domain is a proposition and one whose domain is a degree property. The prediction is thus that an exclamation can only be formed from something which denotes a proposition or something which denotes a degree property: an exclamation cannot be used, for example, to express surprise at a particular individual.

The fact that natural language uses these particular two illocutionary force operators (and not, say, a Proposition E-ForCE and an Individual E-FORCE) is stipulated by the theory. Although there are some ways in which the degree domain differs from the individual domain which make degrees seem to be more appropriate candidates for exclamation - the domain is intrinsically ordered, for instance, and degree properties are unique in their ability to be evaluative - I have no account for why this is the state of affairs in natural language. 


\section{Extensions of the theory}

\subsection{The structure of wh-exclamatives}

The theory predicts that an exclamation can be formed from an expression which denotes a proposition or an expression which denotes a degree property. We've already seen that what denotes a degree property is not straightforward: a whexclamative need not contain overt degree morphology in order to denote a degree property for the purposes of an exclamative: What languages Mimi speaks! can have a gradable reading despite not containing an (overt) gradable adjective (and contrary to a question formed from the same wh-clause).

This way of discussing exclamatives raises another issue: what is the syntax of the wh-clauses used to express exclamatives such that they denote degree properties (rather than e.g. sets of propositions)? There is some cross-linguistic evidence to suggest that the $w h$-clauses forming exclamatives pattern with free relatives, rather than questions, in their syntax and morphology. For instance, in Hebrew the $w h$-clauses which form exclamatives and free relatives both require overt complementizers, but (embedded) constituent questions do not (for additional arguments that the syntax of exclamatives pattern with that of relative clauses, see Rett 2008b: Chapter 4).

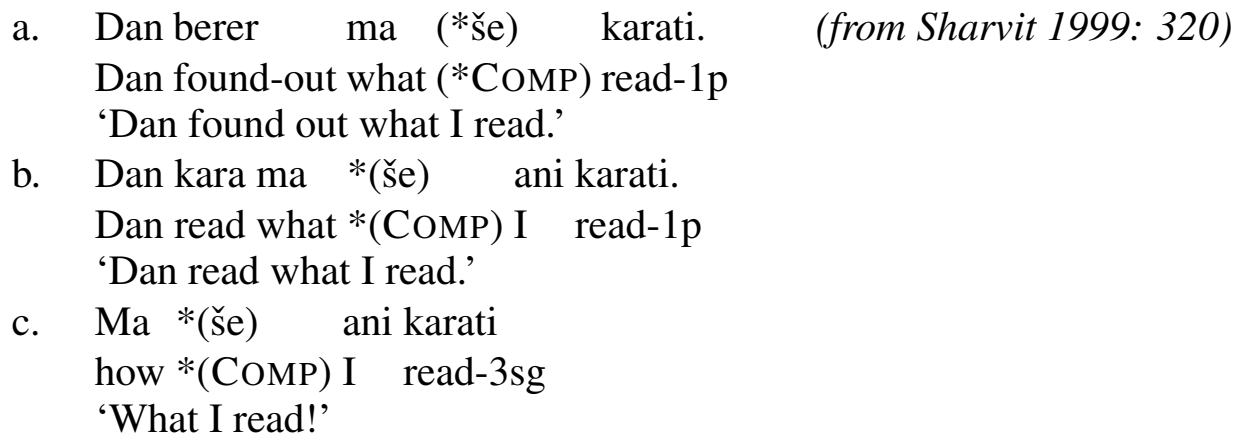

Headed relative clauses like the book which I read denote properties (see Jacobson 1995, Dayal 1996, Caponigro 2004). Free relatives, on the other hand, are typically thought of as denoting the maximal entity which satisfies a property. But the idea that $w h$-exclamatives are expressed with free relatives could be made compatible with Degree E-FORCE if we think of the 'maximal entity' reading associated with free relatives in non-exclamative contexts as being derived from the property denotation of a headed relative via a type-shifter (Jacobson 1995). Specifically, although embedded free relatives combine with a type-shifter to denote a maximal entity, free relatives uttered with Degree E-FORCE would not, and would thus denote degree properties.

The rest of this section is devoted to the discussion of the other two types of exclamatives, nominal and inversion exclamatives, as in (2b) and (2c). 


\subsection{Nominal exclamatives}

The present theory predicts that any construction which denotes a degree property can be used to utter an exclamative. I have already mentioned that headed relative clauses - like the book which I read - denote properties. This means that we predict that a headed relative, if it can denote a degree property, can be used to express an exclamative. This is in fact the case.
a. (Oh, ) The height of that building!
b. (Oh,) The places you'll go!
c. (Oh,) Her way of doing things!

Rett (2008b) discusses a parallel between nominal exclamatives and amount relatives (Carlson 1977, Grosu and Landman 1998) like John put what he could in his pockets and The/What headway Mel made was unsatisfactory. (Among other things, amount relatives, like nominal exclamatives, cannot be formed with indefinites: *Some headway Mel made was unsatisfactory and *Oh, some places you'll go!.) This parallel provides evidence outside of exclamatives that headed relatives can receive amount readings. However there is no such evidence, as far as I know, of headed relatives receiving gradable readings. This provides a further complication to determining the distribution of the gradable predicate $\mathbb{P}$.

As predicted, nominal exclamatives are subject to the Degree Restriction by virtue of the fact that they are expressed with Degree E-FORCE. (21) patterns with its $w h$-phrase counterpart in the Mimi scenario described above.

(Oh,) The languages Mimi speaks!

a. \#individual: surprise that Mimi speaks Portuguese and Romanian

b. amount: surprise that Mimi speaks a large number of languages

c. gradable: surprise that the languages Mimi speaks are $P$ to degree $d$

(21) can only be used to express surprise at either the number of languages Mimi speaks or the degree to which the languages she speaks are some predicate $P$.

Nominal exclamatives are also subject to the Evaluativity Restriction. Imagine a scenario in which Linda expects the amount of children Leon has to be particularly high (or low). However, she discovers that Leon has 3 children, which is, say, the average number of children to have.

\#(Oh,) The number of children Leon has!

Despite the fact that the number of children Leon has was lower than (or higher than) Linda's expectation, Linda's utterance of (22) is not expressively correct because the amount of children Leon has is not significantly high or low relative to the corresponding contextual standards.

It has long been the goal of syntactic studies of exclamatives to account for which constructions can form an exclamative and why (for a clear exposition of this problem, see Michaelis and Lambrecht 1996). Characterizing the domain of 
Degree E-FORCE as a degree property predicts that exclamatives can be formed with both headed relatives and free relatives, given our assumption that the former denote properties in the absence of a type-shifter. It also predicts that both will be subject to the Degree and Evaluativity Restrictions. The third and final type of exclamative, however, is a more unexpected member of this class.

\subsection{Inversion exclamatives}

Exclamatives can also be formed from inversion constructions, as shown below.

a. (Boy,) Does she have a lot of money!

b. (Boy,) Can Meg cook!

By virtue of the fact that these inversion constructions are full sentences displaying subject-auxilliary inversion, we can guess these exclamatives are formed from either declarative sentences with inversion or yes/no questions. If this is the case, we would expect the content of these exclamatives to be either propositions (like other declarative sentences) or sets of propositions (like yes/no questions).

But inversion exclamatives, too, are subject to the Degree and Evaluativity Restrictions, which indicates that their content is instead a degree property. There are three possible interpretations of the inversion exclamative in (24).

(Boy,) Can Robin bake pies!

a. amount: surprise that Robin can bake a large amount of pies

b. gradable: surprise that Robin can bake pies that are $P$ to degree $d$

c. evaluation: surprise that Robin can bake pies ADV to degree $d$

(24) can only have the three interpretations weve already seen in connection with wh- and nominal exclamatives: it can be used to exclaim that the amount of pies Robin can bake is high (the amount reading), that the degree to which the pies Robin can bake are $P$ (delicious) is high (the gradable reading), and that the degree to which Robin can bake pies ADV (skillfully, quickly) is high (the evaluation reading). As before, it's important to see what readings aren't available to inversion exclamatives: (24) cannot be used to express surprise at the proposition that Robin can bake pies.

As with other types of exclamatives, inversion exclamatives are subject to the Evaluativity Restriction. Imagine a scenario in which you expect Mark's son to be quite short, because both Mark and his wife are short. When you meet him, you realize that he is $5^{\prime} 9^{\prime \prime}$, which is (say) an average height for a boy his age. In such a scenario, an utterance of (32) is expressively incorrect. This is because, despite the fact that Mark's son was taller than you expected, he is not tall with respect to the relevant standard of tallness.

\#(Boy,) Is Mark’s son tall! 
The theory of exclamatives presented above is only complete with an account of how the content of an inversion exclamative could be a degree property. I will propose such an account in two steps: first, I'll argue that inversion exclamatives aren't expressed with yes/no questions. Second, I'll suggest an account of how inversion exclamatives denote degree properties by virtue of their inversion.

In her response to Elliott (1974), McCawley (1973) provides an extensive list of morphological, syntactic and semantic differences between yes/no questions and inversion exclamatives. I'll list two of them here (the examples are hers). First, inversion exclamatives seem to be incompatible with overt sentential negation in contrast to yes/no questions in interrogatives.

a. Isnt syntax easy?

b. *(Boy,) Isnt syntax easy!

Second, inversion exclamatives differ from yes/no questions in interrogatives in that they do not permit degree quantifiers like the equative and the superlative.

a. Is syntax as easy as phonology?

b. *(Boy,) Is syntax as easy as phonology!

a. Is she the prettiest girl in your class?

b. *(Boy,) Is she the prettiest girl in your class!

So an account of inversion exclamatives would ideally address two questions: first, how can an inversion construction denote a degree property? And second, why do inversion exclamatives display the unique morphosyntactic properties they do? There is at least one possible account of inversion constructions which connects their semantic nature to their syntactic nature: that the inversion constructions used to express inversion exclamatives denote degree properties via the movement of a null degree operator.

The semantic importance of this operator is to lend a degree reading to a construction which would otherwise not have one. The tree below demonstrates the syntax of this operator. When DegOp is interpreted in its moved position, it lambda-abstracts over the free degree variable, resulting in a set of degrees $d$ which represent how $\mathbb{P}$ the pies Robin bakes are. I assume that the world argument $w$ is bound by lambda-abstraction at the end of the utterance, resulting in (5). I also assume that the degree modifier EVAL (which contributes evaluativity to a form, Rett 2008b) is present in the derivation, although I have not made it explicit here in an attempt to simplify the discussion. 
(29)

(1) $\lambda d \lambda X \cdot \mathbb{P}(w)(X, d) \wedge \operatorname{pies}(w)(X)$

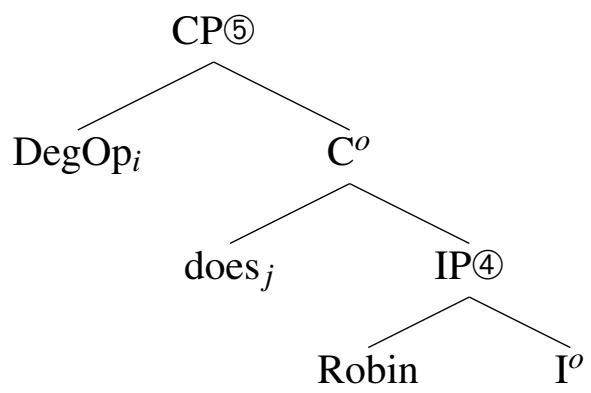

(2) $\lambda X . \mathbb{P}(w)(X, d) \wedge \operatorname{pies}(w)(X)$
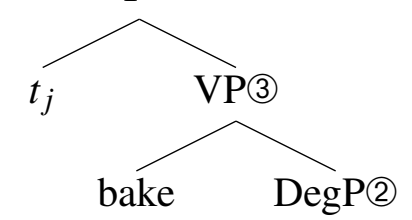

(3) $\lambda y \exists X[\operatorname{bake}(w)(y, X) \wedge \mathbb{P}(w)(X, d) \wedge \operatorname{pies}(w)(X)]$

(4) $\exists X[\operatorname{bake}(w)(r, X) \wedge \mathbb{P}(w)(X, d) \wedge \operatorname{pies}(w)(X)]$

(5) $\lambda d \lambda w \exists X[\operatorname{bake}(w)(r, X) \wedge \mathbb{P}(w)(X, d) \wedge \operatorname{pies}(w)(X)]$

If DegOp moves to spec, CP at LF, we could potentially account for the inversion displayed by these exclamatives. Inversion has been independently associated with the presence of an operator in spec, CP (in, for instance, negative inversion constructions like Never have I been treated so rudely!; Rizzi, 1996). This would also explain the unacceptability of sentential negation in inversion exclamatives, which would be blocked by the presence of Deg,Op.

Postulating a null degree operator base-generated in the spec,DegP of exclamatives in spec,DegP also accounts for the unacceptability of degree quantifiers in inversion exclamatives.

a. (Boy,) Is syntax (*so) easy!

b. *(Boy,) Is she the prettiest girl in your class!

If DegOp is base-generated in the degree argument position of the gradable adjective ( $\mathbb{P}$ in 29), its presence would also block a degree quantifier like the superlative.

A few important points: first, this null DegOp is distinct from the null gradable predicate $\mathbb{P}$, despite the fact that they co-occur in this structure. The above discussion of the wh-exclamative What languages Mimi speaks! shows that $\mathbb{P}$ is needed in some structures (i.e. wh-exclamatives) which don't additionally require DegOp. The acceptability of Boy, does Robin bake delicious pies! shows that DegOp is needed in some structures which don't additionally require $\mathbb{P}$. 
Second, as it stands, this degree operator is very powerful. Unlike e.g. the quantity operator QUANTITY, the distribution of DegOp seems to be restricted to inversion exclamatives. In non-exclamation speech acts, we don't seem to be able to use an inversion declarative to denote a degree property:

a. *Adam is as tall as [CP is Doug tall].

b. *John cooks better than [CP does Robin bake pies].

This relatively restricted distribution of DegOp could ostensibly be the result of a selectional relationship between Degree E-FORCE and DegOp. But it is in the very least unclear how to establish a selectional relationship (syntactic or semantic) between an illocutionary force operator and some element in the form used to express a speech act. As with the distribution of $\mathbb{P}$, I leave this issue open.

An additional complication comes from the relatively restricted syntax of DegOp within the constructions in which it is licensed. Unlike e.g. wh-operators, DegOp doesn't appear to be able to move out of the clause in which it is basegenerated.

a. (Boy,) Did the doctors say she was tall!

b. (Boy,) Does Mary think she's beautiful!

Specifically, if DegOp were a true operator, we would predict that (32b) could have a reading on which the speaker is expressing surprise at the extent to which Mary is beautiful (if DegOp was base-generated with the gradable adjective) as well as a reading on which the speaker is expressing surprise at the extent to which Mary thinks she's beautiful (if DegOp was base-generated in the higher clause with a null adverb associated with Mary's act of thinking). However, only the latter reading is possible, which suggests that inversion exclamatives can only be formed from DegOps which have not crossed a clause boundary. It is not clear to me at the moment how to reconcile the operator-like properties of DegOp with its relatively restricted movement.

In sum, the semantics of inversion exclamatives suggests that they denote degree properties, and the syntax of inversion exclamatives suggests that these degree properties are formed by the movement of a null operator. Such an account of inversion exclamatives encounters two complications: first, it is not clear how to formulate the distribution of DegOp so that it is restricted to inversion exclamatives. And second, given that the movement of DegOp seems to be clause-bound, its syntactic status as an operator seems questionable. A complete understanding of the status of inversion exclamatives requires that these issues be better addressed.

\section{Conclusion}

The first goal of this paper is to show that exclamations expressed with $w h$-clauses, nominals and inversion constructions pattern together - at the exclusion of proposition exclamations - in that they must be used to express surprise at a high degree. 
I've provided an analysis of this generalization which consists of two different illocutionary force operators for exclamation: one whose domain is a proposition and one whose domain is a degree property. Both are functions to an expression of surprise.

The consequences of this analysis are numerous. First, if the content of wh-exclamatives is a degree property, there's reason to think that wh-exclamatives are expressed with free relatives (as opposed to constituent questions, and assuming that these can denote properties in lieu of a type-shifter). I have argued that this claim is supported by morphosyntactic similarities between free relatives and exclamatives cross-linguistically.

Second, the theory predicts that anything which can denote a degree property can be used to express an exclamative. This prediction can be applied relatively easily to account for the existence of nominal exclamatives, given the assumption that they are formed with headed relative clauses, and that headed relative clauses can receive amount readings. However, it is not clear why these clauses can have gradable readings in the environment of an exclamative but not elsewhere.

Finally, extending the analysis to inversion exclamatives provides new insight into what can denote a degree property. Because inversion exclamatives are subject to the Degree and Evaluativity Restrictions, we can reason that their content is a degree property. Their unique morphosyntax suggests an account of their denotation which involves the movement of a null degree operator.

Although this study of exclamatives helps provide insight into the meaning of exclamation, it raises novel questions about degree constructions and how they come to be degree constructions. Specifically, it gives us evidence for null degree predicates $\mathbb{P}$ and ADV, but the distribution of these predicates (their apparent presence in e.g. That's quite a turkey you have and absence in headed relatives like John put what he could in his pockets) remains mysterious. It gives evidence for a null operator DegOp, but it is still unclear how its distribution could be confined to exclamatives. For these reasons, the study of exclamatives could be better served by a more in-depth understanding of the semantics of degree.

\section{References}

Austin, John: 1962, How to Do Things with Words. Oxford University Press.

Bartels, Christine: 1999, The Intonation of English Statements and Questions: A Compositional Interpretation. Garland.

Caponigro, Ivano: 2004, 'The semantic contribution of wh-words and type-shifts: evidence from free relatives crosslinguistically', in R. Young (ed.), Proceedings of SALT XIV, 38-55. CLC Publications.

Carlson, Greg: 1977, 'Amount Relatives', Language 53, 520-542.

Castroviejo-Miró, Elena: 2006, Wh-Exclamatives in Catalan, Doctoral Dissertation, Universitat de Barcelona, Barcelona.

Cresswell, Max: 1976, 'The Semantics of Degree', in B. Partee (ed.), Montague 
Grammar. Academic Press.

Dayal, Veneeta: 1996, Locality in WH-Quantification. Kluwer.

Elliott, Dale: 1974, 'Towards a Grammar of Exclamations', Foundations of Language 11, 231-246.

Gérard, J.: 1980, L'exclamation en français. Niemeyer, Tübingen.

Grimshaw, Jane: 1977, English Wh-Questions and the Theory of Grammar, $\mathrm{PhD}$ Thesis, University of Massachusetts, Amherst, MA.

Grosu, Alexander and Fred Landman: 1998, 'Strange Relatives of the Third Kind', Natural Language Semantics 6, 125-170.

Gutiérrez-Rexach, Javier: 1996, 'The Semantics of Exclamatives', in E. Garrett and F. Lee (eds.), Syntax at Sunset: UCLA Working Papers in Linguistics.

Huddleston, R.: 1993, 'Remarks on the Construction, "You won't believe who Ed has married"', Lingua 91, 175-184.

Jacobson, Pauline: 1995, 'On the Quantificiational Force of English Free Relatives', in E. Bach, E. Jelinek, A. Kratzer, and B. Partee (eds.), Quantification in Natural Languages, 451-486. Kluwer.

Kaplan, David: 1999, 'The meaning of 'ouch' and 'oops". Presented at the Cornell Conference on Context Dependency.

Kennedy, Christopher: 2007, 'Vagueness and Grammar: The semantics of relative and absolute gradable predicates', Linguistics and Philosophy 30, 1-45.

McCawley, Noriko: 1973, 'Boy! Is Syntax easy', Proceedings of the Ninth Regional Meeting of the Chicago Linguistics Society 369-377.

Michaelis, Laura and Knud Lambrecht: 1996, 'The exclamative sentence type in English', in A. Goldberg (ed.), Conceptual Structure, discourse and language, 375-389. CSLI.

Milner, Jean-Claude: 1978, De la Syntaxe à l'interprétation: Quantités, Insultes, Exclamations. Éditions du Seuil, Paris.

Partee, Barbara: 1987, 'Noun Phrase Interpretation and Type-Shifting Principles', in Studies in Discourse Representation Theory and the Theory of Generalized Quantifiers (GRASS 8), 115-143. Foris.

Rett, Jessica: 2008a, 'Antonymy and Evaluativity', in M. Gibson and T. Friedman (eds.), Proceedings of SALT XVII. CLC Publications.

Rett, Jessica: 2008b, Degree Modification in Natural Language, Doctoral Dissertation, Rutgers University.

Rizzi, Luigi: 1996, 'Residual verb second and the Wh- Criterion', in A. Belletti and L. Rizzi (eds.), Parameters and Functional Heads, 63-90. Oxford University Press.

Searle, John: 1969, Speech Acts. Cambridge University Press.

Sharvit, Yael: 1999, 'Connectivity in Specificational Sentences', Natural Language and Linguistic Theory 7, 299-341.

Villalba, Xavier: 2003, 'An Exceptional Exclamative Sentence Type in Romance', Lingua 113, 713-745.

Zanuttini, Rafaella and Paul Portner: 2003, 'Exclamative Clauses: at the SyntaxSemantics Interface', Language 79, 39-81. 